\title{
EVOLUTION OF STRUCTURE AND PROPERTIES OF NICKEL-ENRICHED Ti-Ni SHAPE MEMORY ALLOY SUBJECTED TO COMPRESSIVE DEFORMATION
}

\author{
1,2,3Victor KOMAROV, ${ }^{2} \mid$ rina KHMELEVSKAYA, ${ }^{1,2}$ Roman KARELIN, ${ }^{1}$ Vladimir YUSUPOV, \\ ${ }^{2}$ Ivan POSTNIKOV, ${ }^{3}$ Grzegorz KORPALA, ${ }^{3}$ Rudolf KAWALLA, ${ }^{3}$ Ulrich PRAHL, \\ ${ }^{1}$ Sergey PROKOSHKIN \\ ${ }^{1}$ Baikov Institute of Metallurgy and Materials Science, RAS, Moscow, Russia, vickomarov@gmail.com \\ ${ }^{2}$ National University of Science and Technology MISIS, Moscow, Russia, khmel@tmo.misis.ru \\ 3TU Bergakademie Freiberg, Germany, grzegorz.korpala@imf.tu-freiberg.de
}

https://doi.org/10.37904/metal.2020.3623

\begin{abstract}
The effect of compressive deformation of the nickel-enriched Ti-Ni shape memory alloy in a temperature range of 100 to $900{ }^{\circ} \mathrm{C}$ on phase composition, microstructure, mechanical and functional properties was studied. The temperature ranges of dynamic recovery, polygonization and recrystallization were determined as a result of comparative optical microscopy, XRD, DSC studies, HV measurements and shape recovery testing. Lowering of the compressive deformation temperature is accompanied by an increase in a hardness value from 280 to $350 \mathrm{HV}$ and leads to decrease in average grain size from 33 to $16 \mu \mathrm{m}$. The dispersion hardening leads to an increase in shape recovery properties. The optimum deformation temperature range for thermomechanical treatment of Ti-Ni SMA from the viewpoint of ultrafine-grained structure and high functional properties formation was determined as 400 to $600^{\circ} \mathrm{C}$.
\end{abstract}

Keywords: Shape memory alloys, Ti-Ni, thermomechanical treatment, structure parameters

\section{INTRODUCTION}

The Ti-Ni shape memory alloys (SMA) belong to one of the most promising and actively developing functional materials [1-6]. Expansion of the application scope and increase in the complexity of medical devices using shape memory effect lead to formation of stricter requirements for the functional properties (FP) of Ti-Ni SMA. One of the most effective ways to control the FP is a thermomechanical treatment (TMT), which allows creating a wide spectrum of structures from a polygonized substructure to an ultrafine-grained structure [7-9]. The refinement of the structure is usually achieved by lowering of the deformation temperature and increasing of accumulated strain [9-11]. For obtaining of the ultrafine-grained structure in Ti-Ni alloys, various modes of severe plastic deformation are used: equal channel angular pressing [12,13], rotary forging [14], MaxStraindeformation [11,15] and high pressure torsion [16,17]. The development of new TMT technologies for producing of Ni-rich Ti-Ni SMA which use lower deformation temperatures (below the recrystallization temperature) for effective structure refinement requires knowledge about the temperature ranges of hardening and softening processes during deformation in a wide temperature range. The difficulty in determination of Ti$\mathrm{Ni}$ SMA optimum deformation modes may be explained by the lack of data about the forming structure and properties during TMT at temperatures below $600{ }^{\circ} \mathrm{C}$. This is one of the constraining factors of their practical application and manufacturing. Thus, for further testing of different TMT modes at lower temperatures, it is necessary to know the temperature ranges and details of dynamic processes of structure formation. This work is aimed at determining of the optimum regimes of thermomechanical treatment for manufacturing Ti-Ni SMA with high FP level. 


\section{EXPERIMENTAL}

Compression tests of the nickel-enriched Ti-Ni alloy containing 50.9 at\% Ni were performed at a deformation rate of $1 \mathrm{~s}^{-1}$ with accumulated logarithmic strain $e=0.5$ in the temperature range from 100 to $900{ }^{\circ} \mathrm{C}$. Before deformation, the samples of $5 \mathrm{~mm}$ in diameter and $10 \mathrm{~mm}$ in height were subjected to a reference treatment (RT) included heating at $700{ }^{\circ} \mathrm{C}$ for $0.5 \mathrm{~h}$ and water quenching. As a result, the following characteristic temperatures of the direct $\left(M_{s}, M_{f}\right)$ and reverse $\left(A_{s}, A_{f}\right)$ martensitic transformations after RT were determined by DSC method: $M_{s}=-80^{\circ} \mathrm{C}, M_{f}=-95^{\circ} \mathrm{C}, A_{s}=-65^{\circ} \mathrm{C}, A_{f}=-45^{\circ} \mathrm{C}$. The structure and phase composition after deformation by compression at a given temperature were examined at room temperature by optical microscopy and X-ray diffractometry. The average grain size was determined by the linear intercept method. The mechanical properties were evaluated by Vickers hardness tests. Measurements were carried out at seven points in different parts of the sample at room temperature using a "LECOM 400-A" tester under a load of $1 \mathrm{~N}$. The completely recoverable strain was evaluated by a thermomechanical method including deformation by bending in liquid nitrogen and subsequent heating for shape recovery.

\section{RESULTS AND DISCUSSION}

\subsection{Analysis of mechanical properties}

The strain in the compressed cylindrical sample is not evenly distributed. Analysis of the distribution of hardness values shows its difference in the range of 10-20 HV between the central and peripheral parts of the samples. Figure 1 shows the average values of hardness for samples after deformation at various temperatures. Lowering the deformation temperature from 900 to $100{ }^{\circ} \mathrm{C}$ is accompanied by an increase in hardness from 280 to $350 \mathrm{HV}$, which indicates an increase in defective structure. At a deformation temperature of $600{ }^{\circ} \mathrm{C}$ and higher, the hardness approaches the level of the reference treatment, which indicates the progress of the recrystallization processes.

\subsection{Microstructure analysis}

Optical microscopy study of the obtained structure of the alloy reveals that the average grain size of B2austenite measured after deformation at temperatures from 100 to $600{ }^{\circ} \mathrm{C}$, increases slightly with increasing in deformation temperature from 16 to $22 \mu \mathrm{m}$ (Figure 1), while the elongated shape of the grain is preserved.

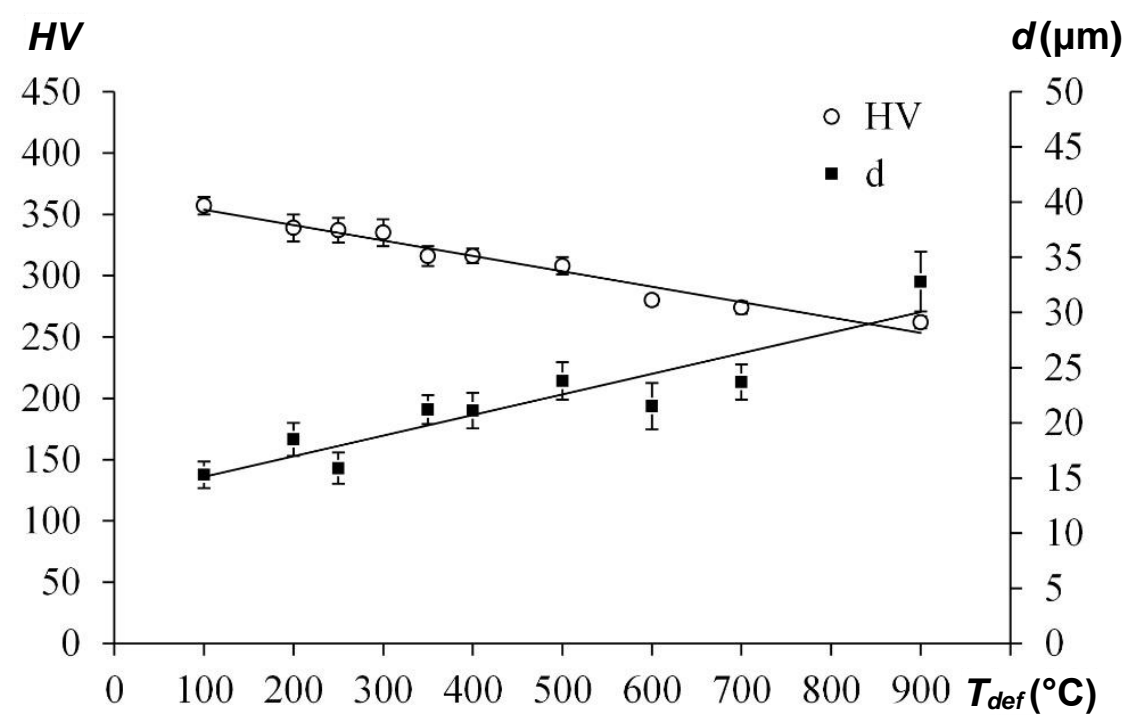

Figure 1 Dependence of changes in hardness (HV) and grain size $(d)$ on deformation regimes 
Optical microscopy analysis also confirms that the structure obtained by compressive deformation at temperatures from 100 to $600^{\circ} \mathrm{C}$ is not uniform. The study of the structure over the entire field of the thin section showed the presence of regions with elongated, predominantly oriented grains in the central part and with approximately equiaxed grains in the peripheral part (Figures $2 \mathbf{a}, \mathbf{b}$ ). The deformation at $700^{\circ} \mathrm{C}$ leads to the dynamic recrystallization development and formation of small new grains, the number of which at the edge of the thin section is much larger than in the center. At the same time, the average grain size does not practically change in comparison with RT and equals $23 \mu \mathrm{m}$ (Figure 2d). An increase in the deformation temperature to $900{ }^{\circ} \mathrm{C}$ leads to complete recrystallization and an increase in the average equiaxed grain size to $33 \mu \mathrm{m}$ (Figure 2c). The obtained patterns are consistent with the general concepts of structure formation of Ti-Ni SMA in terms of deformation [18].

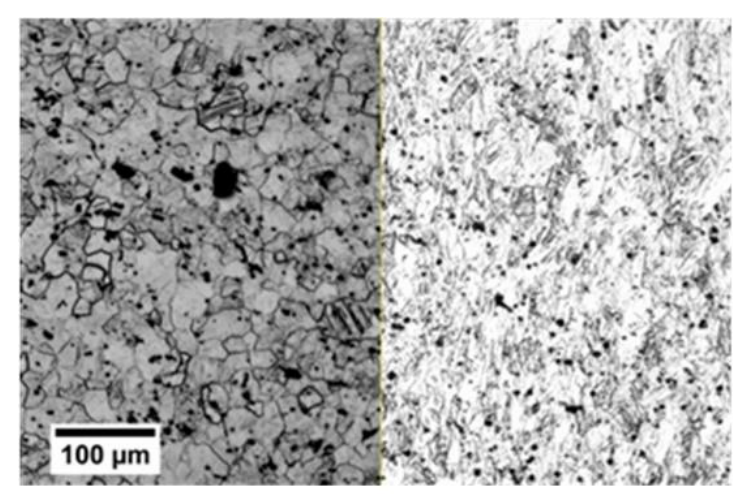

a

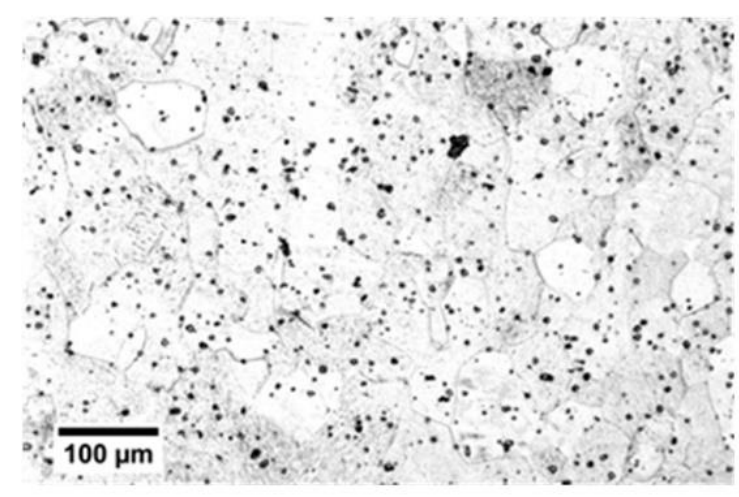

C

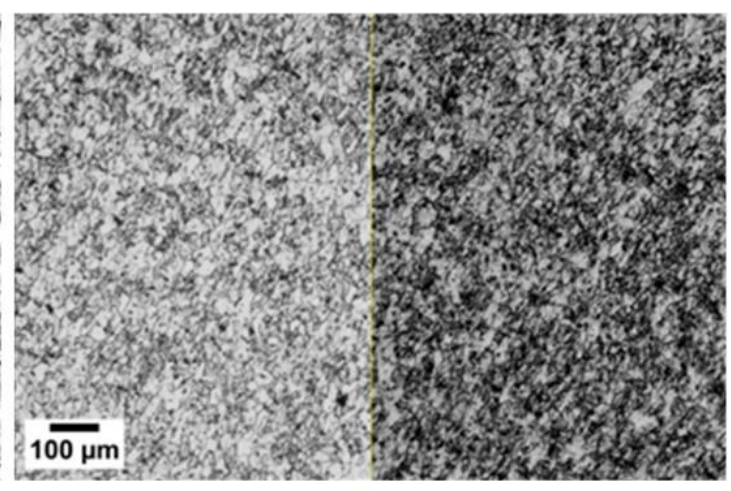

b

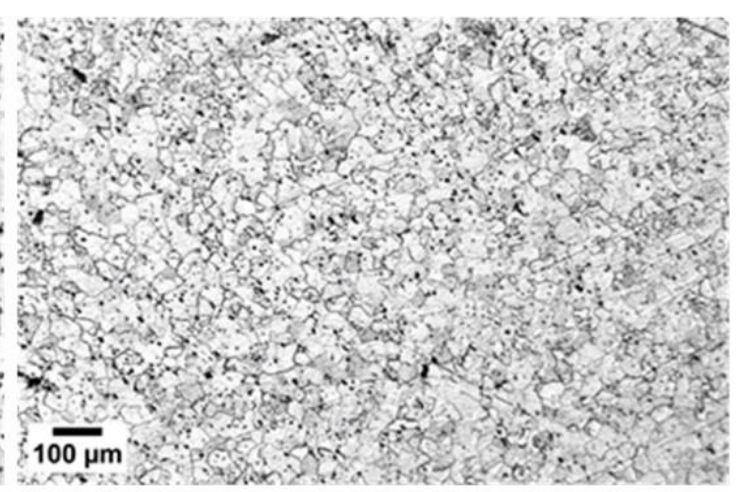

d

Figure 2 Structure of nickel-enriched Ti-Ni SMA after deformation at (a) $\mathrm{T}=100^{\circ} \mathrm{C}$, (b) $\mathrm{T}=600{ }^{\circ} \mathrm{C}$ (central and peripheral parts) and (c) $\mathrm{T}=900^{\circ} \mathrm{C}$, and (d) after reference treatment

\subsection{X-ray diffractometry analysis}

After RT, the alloy has the ordered BCC structure of B2-austenite phase at room temperature. Deformation in the temperature range of $100-900^{\circ} \mathrm{C}$ does not lead to changes in the phase composition. The position of the $\{110\} \mathrm{B} 2$ line peak varies within $\pm 0.052 \theta$ degrees which indicates the absence of significant macrostresses in the alloy.

The dependence of the $\{110\}$ B2 X-ray line width on the deformation temperature is shown in Figure 3. It decreases as the deformation temperature increases, first, slowly (up to $300{ }^{\circ} \mathrm{C}$ ), then rapidly (from 300 to $600^{\circ} \mathrm{C}$ ), and then stabilizes. Such change in the X-ray line width indicates a decrease in the degree of crystal lattice defectness due to the successive development of dynamic recovery, polygonization, and recrystallization processes. 


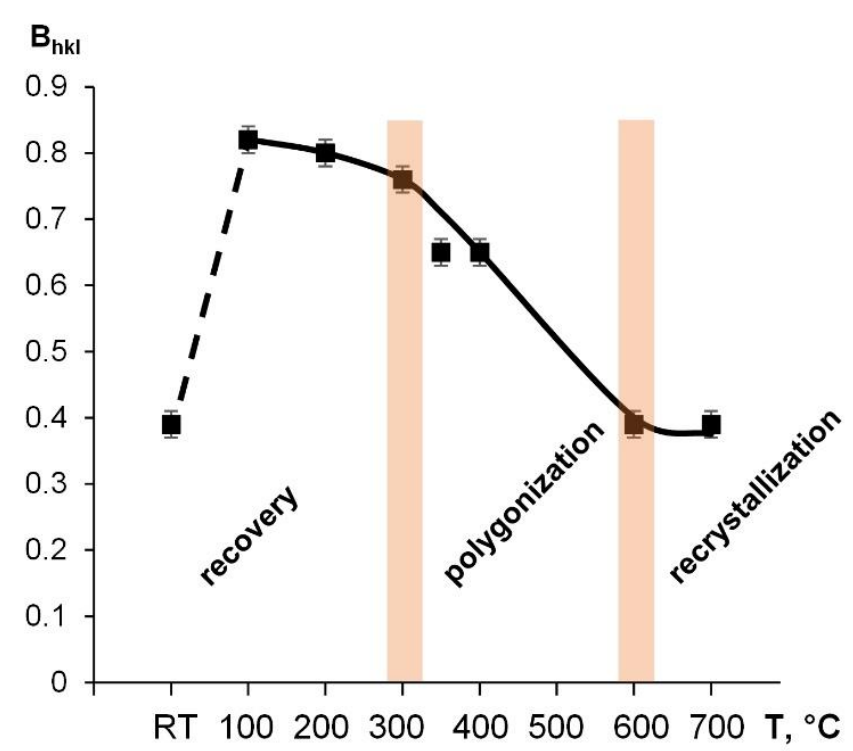

Figure 3 Dependence of the $\{110\}$ B2-austenite X-ray line width on deformation temperature

A comparative study of Ti-Ni SMA structure, phase formation and changes in hardness values in a wide range of deformation temperatures $\left(100-900{ }^{\circ} \mathrm{C}\right)$ allow to determine the boundaries of the temperature regions of dynamic softening processes under conditions of deformation (Figure 3). The dynamic recovery region of the alloy is $100-300{ }^{\circ} \mathrm{C}$, which follows from the low softening processes development and high structure defectness. The dynamic polygonization range is $300-600{ }^{\circ} \mathrm{C}$, as evidenced by the accelerated decrease in the width of the $\mathrm{X}$-ray line. The dynamic recrystallization range lies above $600^{\circ} \mathrm{C}$ that is evidenced by the new recrystallized grains formation and return of the X-ray line width to the level of RT.

\subsection{Analysis of functional properties}

The initial strain in the shape recovery experiment was induced in liquid nitrogen (below $M_{f}$ temperature) and estimated as the value of total recoverable strain $\left(\varepsilon_{r t}\right)$ due to the realization of the shape memory effect (SME) and superelasticity (SE). After all deformation regimes, the completely recoverable strain was not less than 7 $\%$. The maximum values of the completely recoverable strain $\varepsilon_{r t}=9 \%$ were obtained after deformation in the $400-600{ }^{\circ} \mathrm{C}$ range. It can be explained by the intensive realization of dispersion hardening processes due to precipitation of $\mathrm{Ti}_{3} \mathrm{Ni}_{4}$ phase particles in this temperature range $[19,20]$. A change in the ratio of the components of the total recoverable strain $\varepsilon_{r t}$ with the deformation regime changes was observed. The ratio of the contributions of SME and SE to the total recoverable strain after all regimes was in favor of the SME. After deformation at $300{ }^{\circ} \mathrm{C}$, these fractions were close in magnitude $\varepsilon_{r t}(\mathrm{SE})=6.4 \%$ and $\varepsilon_{r t}(\mathrm{SME})=5.4 \%$ ). The use of different deformation regimes makes it possible to change the ratio of the fractions of the total recoverable strain components that can be used in the design of devices which operation is exclusively based on the SE or SME.

\section{CONCLUSION}

Lowering of the compressive deformation temperature from 900 to $100{ }^{\circ} \mathrm{C}$ of nickel-enriched Ti-Ni SMA is accompanied by an increase in hardness from 280 to $350 \mathrm{HV}$ and leads to formation of structure with an average size from 33 to $16 \mu \mathrm{m}$. The temperature regions of the development of dynamic softening processes in nickel-enriched Ti-Ni SMA are established, as follows: dynamic recovery in the range of $100-300{ }^{\circ} \mathrm{C}$; dynamic polygonization in the range $300-600{ }^{\circ} \mathrm{C}$, dynamic recrystallization above $600{ }^{\circ} \mathrm{C}$. The highest shape recovery characteristics (a total recovery strain of $9 \%$ ) were obtained after deformation in the temperature 
range of $400-600{ }^{\circ} \mathrm{C}$. Thus, the temperature range $400-600{ }^{\circ} \mathrm{C}$ is the most promising from the viewpoint of ultrafine-grained structure and high functional properties formation in nickel-enriched Ti-Ni SMA.

\section{ACKNOWLEDGEMENTS}

\section{The reported study was funded by RFBR, project number 19-33-60090.}

\section{REFERENCES}

[1] OTSUKA, K., REN, X. Recent developments in the research of shape memory alloys. Intermetallics. 1999, vol. 7, no. 5, pp. 511-528.

[2] SHARIAT, B.S., MENG, Q., MAHMUD, A. S., WU, Z., BAKHTIARI, R., ZHANG, J., LIU, Y. Functionally graded shape memory alloys: Design, fabrication and experimental evaluation. Materials \& Design. 2017, no. 124, pp. 225-237.

[3] JANI, J.M., LEARY M., SUBIC A., GIBSON M.A. A review of shape memory alloy research, applications and opportunities. Materials \& Design. 2014, vol. 56, pp. 1078-1113.

[4] RESNINA, N., RUBANIK, V., Eds. Shape Memory Alloys: Properties, Technologies, Opportunities. Praffikon: Trans. Tech. Publications, 2015.

[5] SUN, Q., MATSUI, R., TAKEDA, K., PIECZYSKA, E. Advances in Shape Memory Materials: In Commemoration of the Retirement of Professor Hisaaki Tobushi. Springer, 2017. vol. 73.

[6] SELLITTO, A., RICCIO, A. Overview and future advanced engineering applications for morphing surfaces by shape memory alloy materials. Materials. 2019, vol.12, no. 5, pp. 708.

[7] VALIEV, R. Z., ALEKSANDROV, I. V. Nanostructural Materials Obtained by Severe Plastic Deformation. Integratsiya, Moscow, 2000.

[8] VALIEV, R., ESTRIN, Y., HORITA, Z., LANGDON, T., ZEHETBAUER, M., ZHU, Y. Producing bulk ultrafinegrained materials by severe plastic deformation. JOM. 2006, vol. 58, pp. 33-39.

[9] SABIROV, I., ENIKEEV, N., MURASHKIN, M., VALIEV, R. Bulk nanostructured materials with multifunctional properties. New York: Springer, 2015.

[10] PIPPAN, R., WETSCHER, F., HAFOK, M., VORHAUER, A., SABIROV, I. The limits of refinement by severe plastic deformation. Advanced Engineering Materials. 2006, vol. 8, no.11, pp. 1046-1056.

[11] KOMAROV, V., KHMELEVSKAYA, I., KARELIN, R., PROKOSHKIN, S., ZARIPOVA, M., ISAENKOVA, M., KORPALA, G., KAWALLA, R. Effect of biaxial cyclic severe deformation on structure and properties of Ti-Ni alloys. Journal of Alloys and Compounds. 2019, vol. 797, pp. 842-848.

[12] VALIEV, R. Z., LANGDON, T. G. Principles of equal-channel angular pressing as a processing tool for grain refinement. Progress in Materials Science. 2006, vol. 51, pp. 881-981.

[13] KHMELEVSKAYA, I.Y., KARELIN, R.D, PROKOSHKIN, S. D., ISAENKOVA, M.G, PERLOVICH, YU. A., FESENKO, V. A., KOMAROV, V.S., ZARIPOVA, M.M. Features of nanostructure and functional properties formation in Ti-Ni shape memory alloys subjected to quasi-continuous equal channel angular pressing. IOP Conference Series: Materials Science and Engineering. 2019, vol. 503, pp. 012024.

[14] PROKOSHKIN, S., KHMELEVSKAYA, I., ANDREEV, V., KARELIN, R., KOMAROV, V., KAZAKBIEV, A. Manufacturing of Long-Length Rods of Ultrafine-Grained Ti-Ni Shape Memory Alloys. Mater. Sci. Forum. 2018, vol. 918, pp. 71-76.

[15] KHMELEVSKAYA, I., KOMAROV, V., KAWALLA, R., PROKOSHKIN, S., KORPALA, G. Effect of Biaxial Isothermal Quasi-Continuous Deformation on Structure and Shape Memory Properties of Ti-Ni Alloys, Journal of materials engineering and performance. 2017, vol. 26, pp. 4011-4019.

[16] SHAHMIR, H., NILI-AHMADABADI, M., HUANG, Y., JUNG J. M., KIM, H. S., LANGDON, T. G. Shape memory characteristics of a nanocrystalline TiNi alloy processed by HPT followed by post-deformation annealing. Materials Science and Engineering: A. 2018, vol. 734, pp. 445-452.

[17] SUNDEEV, R. V., GLEZER, A. M., SHALIMOVA, A. V. Crystalline to amorphous transition in solids upon highpressure torsion. Journal of alloys and compounds. 2014, vol. 611, pp. 292-296 
[18] YAMAUCHI, K., OHKATA, I., TSUCHIYA, K., MIYAZAKI, S. Shape memory and superelastic alloys. Cambridge: Woodhead Publishing, 2011.

[19] PUSHIN, V. G., KURANOVA, N. N., KOUROV, N. I., VALIEV, R. Z., KOROLEV, A. V., MAKAROV, V. V., UKSUSNIKOV, A. N. Effect of heat treatment on structural and phase transformations in the $\mathrm{Ti}_{49.5} \mathrm{Ni} 50.5$ alloy amorphized by high-pressure torsion. The Physics of Metals and Metallography. 2013, vol. 114, no. 6, pp. 488502.

[20] JIANG, S. Y., ZHAO, Y. N., ZHANG, Y. Q., HU, L., LIANG, Y. L. Effect of solution treatment and aging on microstructural evolution and mechanical behavior of NiTi shape memory alloy. Transactions of Nonferrous Metals Society of China. 2013, vol. 23, no. 12, pp. 3658-3667. 